ANUARIO DE Estudios MEDIEVALES

42/2, julio-diciembre de 2012, pp. 479-499

ISSN 0066-5061

doi:10.3989/aem.2012.42.2.12

\title{
COMPETENCIA, MERCADO E INTERVENCIONISMO EN EL COMERCIO DE CARNE EN LA EUROPA BAJOMEDIEVAL. LOS EJEMPLOS DE BARCELONA Y RUÁN ${ }^{1}$
}

\author{
COMPETITION, MARKET AND INTERVENTIONISM: \\ THE MEAT TRADE IN EUROPE DURING THE LATE MIDDLE AGES. \\ THE EXAMPLES OF BARCELONA AND ROUEN
}

\author{
RAMÓN AGUSTÍN BANEGAS LÓPEZ² \\ Universitat de Barcelona
}

\begin{abstract}
Resumen: La carne es un producto esencial en la alimentación medieval y su escasez generará problemas sociales, especialmente en el mundo urbano; por tanto, un elemento fundamental de la política municipal será vigilar el correcto abastecimiento de este producto. En este artículo se analizará la estructuración del mercado de la carne en dos ciudades europeas que comparten dimensiones demográficas y estructuras económicas, pero que están muy alejadas desde el punto de vista geográfico e institucional. A través del análisis del mercado de la carne en Barcelona y en Ruán se intentará ver cómo afrontan el problema del abastecimiento dos ciudades con marcos institucionales y estrategias políticas muy diferentes.
\end{abstract}

Palabras clave: carne; abastecimiento urbano; corporación de oficio; competencia; monopolio; intervencionismo; Barcelona; Ruán; s. XIV; s. XV.

\begin{abstract}
Meat is a main staple in medieval diets and shortage of meat might challenge the social peace, particularly in an urban context. Institutions and politics had a strong influence on the evolution of the meat trade. The strategies of royal officials and municipal governments were essential to understanding the problems of meat supply and how they were solved. This article analyses the structures of the meat market in two European cities: Barcelona and Rouen. Two cities with the same number of inhabitants and the same economic structures, but which are geographically far apart, and had different institutional structures. The different politics applied to the meat business were the cause of the divergent evolution of the butcher's trade in these two cities.
\end{abstract}

Keywords: meat; urban supply; guild; competition; monopoly; interventionism; Barcelona; Rouen; 14 th century; 15 th century.

\section{SUMARIO}

1. Introducción.- 2. La carnicería: trabajo manual y negocio.- 3. La intervención indirecta en el mercado de la carne: el caso de Ruán.- 4 . La intervención directa en el mercado de la carne: el caso de Barcelona.- 5. Conclusiones.- 6. Bibliografía citada.

${ }^{1}$ Abreviaturas utilizadas: ADSM = Archives départémentales de la Seine Maritime; AHCB = Arxiu històric de la ciutat de Barcelona; AHPB = Arxiu històric de protocols de Barcelona; AMR $=$ Archive municipale de Rouen; $\mathrm{CC}=$ Consell de Cent; ORF = Ordonnances des Rois de France.

${ }^{2}$ El proceso de investigación de este artículo se ha realizado gracias a la financiación de la ayuda de movilidad posdoctoral en el extranjero MICINN. Referencia: 2008-0025. 


\section{INTRODUCCIÓN}

Durante la Baja Edad Media, en toda la Europa occidental, la carne era un producto fundamental en la alimentación de todas las clases urbanas ${ }^{3}$. Si el pan era el alimento central en todas las dietas, el principal companaje era la carne, hasta el punto de que su escasez o excesivo precio podían generar problemas de orden público y poner en un aprieto a los titulares del poder político ${ }^{4}$. El control del mercado de carne se convirtió en una importante preocupación para las autoridades, mantener un buen abastecimiento de carne a un buen precio fue un objetivo primordial en su política de abastecimiento; ahora bien, las estrategias para lograr este objetivo fueron diversas, como se verá a lo largo de este estudio. En algunas ciudades se optó por una intervención directa a través de la fijación de precios y la concesión de monopolios y, en otras, se prefirió favorecer la competencia interna y permitir una cierta autorregulación por parte de los propios carniceros. Los principales afectados por las políticas de regulación del mercado de la carne eran los propios protagonistas de este mercado: carniceros, comerciantes de ganado, etc. El papel en el mercado de cada uno de estos elementos, su poder económico, conjuntamente con sus relaciones internas fueron fundamentales para vertebrar su diálogo con el poder. En las dos ciudades estudiadas, los principales actores económicos en el proceso de abastecimiento de carne serán los carniceros -si bien esta situación sufrirá una evolución a lo largo de los dos siglos- y su mayor o menor control del mercado, su capacidad económica y sus solidaridades internas serán fundamentales en la evolución del grupo profesional y en la propia evolución del mercado de la carne.

En este artículo se analizará en primer término qué se entiende por carnicero en las ciudades de la Baja Edad Media, su papel en la cadena comercial de la carne, su relación con el trabajo manual, sus capacidades económicas, etc. para después analizar el papel que ejercen los poderes públicos en el mercado de la carne, intentando observar sus relaciones con los carniceros y su intervención en el negocio. Con el objetivo de tener una visión completa de la problemática planteada también se analizarán las relaciones internas de los carniceros de ambas ciudades y cómo influyen éstas en los conflictos que mantendrán con las autoridades municipales y la monarquía. Para realizar este análisis se priorizarán dos casos concretos: el de la ciudad de Ruán y el de la ciudad de Barcelona, dos ciudades que tenían al final de la Edad Media una población semejante y una estructura económica también similar pero que, en cambio, contaban con instituciones y estructuras políticas muy diferentes.

${ }^{3}$ La bibliografía sobre el papel de la carne en las dietas urbanas bajomedievales es muy amplia, gracias al desarrollo que ha tenido la Historia de la Alimentación en las últimas décadas. Para la Corona de Aragón algunas obras fundamentales serían: A. Riera, Estructura social y sistemas alimentarios, pp. 193-205; idem, Jerarquía social y desigualdad alimentaria, pp. 193-195; idem, Pobreza y alimentación, pp. 39-72; J.V. García, La jerarquía de la mesa. En el caso del norte de Francia, algunas obras fundamentales serían: B. Laurioux, Manger au Moyen Âge; B. Laurioux, Une histoire culinaire du Moyen Âge; B. Clavel, L'animal dans l'alimentation médiévale et moderne. Un buen resumen sobre el papel de la carne en las mesas urbanas bajomedievales en la Europa occidental se puede encontrar en R.A. Banegas, Consumption of meat, pp. 63-86.

${ }^{4}$ Un ejemplo lo encontramos en Barcelona el 19 de septiembre de 1455 cuando Joan Bach conseller de la ciudad de Barcelona comunica al resto de sus colegas que "la jornada d'ahir que fou dijous al deprés dinar nos trobave carn en Barchinona, que la gent ne pogués haver en tant que la ciutat vench en punt de una gran remor e fou dupte que no·s seguís algun scàndol" (en la jornada de ayer que fue jueves después de comer no se encontraba carne en Barcelona, que la gente pudiese tener, asî la ciudad llegó al punto de un gran rumor que podía seguir en algún escándalo). AHCB, CC, Registre de deliberacions II-9, f. 183v. 


\section{LA CARNICERÍA: TRABAJO MANUAL Y NEGOCIO}

Según el diccionario de Antonio de Nebrija de 1495 un carnicero es aquel que vende carne ${ }^{5}$. En la definición, Nebrija no aclara si el carnicero vende carne a través de uno o más asalariados o si lo hace él mismo en la tabla de carnicería. Según un artículo de Santiago Aguadé y María Dolores Cabañas, en Cuenca, durante el siglo XV, el término carnicero definía a un miembro de la aristocracia comercial de la ciudad que se dedicaba principalmente a la ganadería y que arrendaba las tablas de carnicería de la ciudad para vender carne a través de cortadores asalariados ${ }^{6}$; una realidad semejante se encuentra en Murcia o Burgos, donde en la segunda mitad del siglo XV los proveedores de carne de la ciudad no son los mismos que los cortadores que trabajan en las tablas de carnicería ${ }^{7}$. La estructuración de la carnicería en estas ciudades castellanas difiere de la que encontramos en Barcelona o Ruán durante el siglo XIV y la primera mitad del XV, en las dos ciudades los carniceros son propietarios del ganado que ellos mismos sacrifican y despiezan en las tablas de carnicería con la ayuda de asalariados.

Otro elemento a tener en cuenta a la hora de analizar el negocio de la carnicería es que los carniceros no solo abastecen la ciudad de carne, sino también de otros productos. Para conocer de primera mano todo lo que producen y ponen en el mercado los carniceros y su valor podemos tomar como ejemplo el estudio hecho por las autoridades municipales de Ruán en 1551 para averiguar el precio real de la carne en la ciudad. Para lograr su objetivo, los consejeros de la ciudad contratan a dos carniceros para que les hagan un informe sobre los precios de los animales y los precios de venta de las diferentes partes del animal tras el proceso de sacrificio, desollado y despiece. Los carniceros normandos dividen los productos finales en cuatro categorías en el caso de los bovinos: carne, cuero, entrañas y sebo; y cinco en el caso de los ovinos: carne, cuero, entrañas, sebo y lana. Según este estudio, en el caso del buey el $14,7 \%$ del producto de la venta proviene del cuero; el 2,39\% de las entrañas -incluida la cabeza- el 11,4\% del sebo y el $71,4 \%$ de la carne. En el caso de los carneros, el $74,5 \%$ proviene de la carne y el sebo; el $21,8 \%$ del cuero y la lana y el 3,64\% de las entrañas y la cabeza ${ }^{8}$. Por tanto, los carniceros no solo proveen de carne la ciudad, sino que además aportan materias primas para otros oficios urbanos como el sebo para los candeleros, cuero para los curtidores y lana para los pelaires. El ejemplo de Ruán es extensible a la mayoría de las ciudades europeas, en el caso de Barcelona, por ejemplo, se ha conservado un contrato entre dos carniceros donde uno entrega todas las entrañas de los animales que sacrifique a su colega por un precio fijo semanal ${ }^{9}$. También está documentado un conflicto entre los carniceros y los curtidores por el precio de los cueros ${ }^{10}$. De igual manera se sabe que los carniceros fabricaban candelas de sebo, ya que los miembros del gobierno municipal se quejan a final del siglo XV de su baja calidad ${ }^{11}$.

Si analizamos el negocio de la carnicería en Barcelona, se puede percibir que vive una importante evolución a lo largo de los dos últimos siglos de la Edad Media.

${ }^{5}$ L. Nieto, M. Alvar, Nuevo tesoro lexicográfico del español, pp. 2180-2181.

${ }^{6}$ S. Aguadé, M.D. Cabañas, Comercio y sociedad urbana, pp. 504-516.

7 J.A. Bonachía, Abastecimiento urbano, pp. 85-161; M.A. Marín, Las carnicerías y el abastecimiento, pp. 51-99.

${ }^{8}$ ADSM, AMR, Chartrier 113-2 [11-10-1551].

${ }^{9}$ AHPB, Joan Nadal, 54/3, f. 13r.

${ }^{10}$ AHCB, CC, Registre de deliberacions, II- 18, f. 170r.

${ }^{11}$ AHCB, CC, Registre de deliberacions, II- 31, f. 52v. 
Durante la primera mitad del siglo XIV, en Barcelona había 95 tablas de carnicería repartidas entre los cuatro grandes espacios de sacrificio y venta de carne de la ciudad: la Carnisseria Major, la Carnisseria del Mar, la Carnisseria de la Boqueria y la Carnisseria del Pont de Campderà. En los 15 contratos profesionales ${ }^{12}$, firmados por los carniceros durante la primera mitad del siglo, aparecen un total de 109 firmantes que se identifican como carniceros. De estos 109 se han identificado 16 en los capbreus, que analizó Pere Ortí, de las rentas de la Carnicería Mayor y de la Boquería, correspondientes a los años 1343 y 1365. Según los capbreus, estos 16 carniceros tienen arrendadas entre estos años una o más tablas de carnicería en la Carnicería Mayor y uno tiene arrendada una tabla en la carnicería de la Boquería. Una parte importante de estos carniceros se dedicaría directamente al trabajo de la carnicería y otra parte, los más ricos y poderosos, delegarían el trabajo en manos de asalariados. Seguramente ese sería el caso de Bernat Olzina, que en el capbreu de la Carnicería Mayor de 1365 se identifica como mercader con la propiedad útil de tres tablas; pero también sería el caso de otros que se identifican en todos los documentos como carniceros, pero que tienen la propiedad útil de más de una tabla, como es el caso de Pere Bargalló, Bernat Ferrer o Bernat Citjar $^{13}$. Tampoco se ha de descartar que estos carniceros más ricos y poderosos utilizasen en las tablas a familiares; la aparición reiterada de hermanos e hijos en la firma de los contratos de sociedad, nos ayudan a perfilar la estructuración familiar del negocio.

En general, en la primera mitad del siglo XIV, el negocio de la carnicería en Barcelona se estructura a partir de sociedades de carniceros, los cuales ponen en común sus capitales para comprar el ganado en las ferias y mercados que se realizan en las rutas transhumantes y traerlo hasta la ciudad ${ }^{14}$. Una vez en la ciudad, el ganado es repartido según el capital puesto por cada carnicero y la sociedad se disuelve. Este sistema permite la existencia de un gran número de pequeños carniceros en la ciudad que pueden afrontar los importantes gastos que supone comprar y traer los carneros desde las ferias del Pirineo, la Plana de Lleida, las montañas de Castellón o Aragón, hasta Barcelona ${ }^{15}$. La creación de compañías da una gran capacidad económica a los carniceros, los cuales han logrado una importante integración vertical del negocio en su beneficio, ya que desde la compra de los animales en los lugares de cría, hasta la venta al menor de la carne y otros derivados no hay intermediarios.

La Peste Negra provocará una importante reducción del número de carniceros a consecuencia de la competencia, lo que permitió una primera acumulación de capitales. Un reflejo de este hecho será el acaparamiento de tablas de carnicería por parte de algunos carniceros, como la familia Bargalló, que en 1343 no posee ninguna tabla y en 1365 acumula la propiedad útil de siete tablas en la Carnicería Mayor, o la familia Citjar que, como los Bargalló, en 1343 no aparece como propietaria útil de ninguna tabla en la Carnicería Mayor y en 1365 entre Bernat Citjar i Jaume Citjar, tienen tres ${ }^{16}$, iniciando así su proceso de ascenso económico, que culminará en la segunda mitad del siglo XV cuando los Citjar se coronen como la familia de carniceros más importante de la ciudad.

1213 son contratos donde diferentes compañías de carniceros nombran procurador a uno de los socios para comprar carneros para el conjunto de la sociedad; dos contratos, son contratos de assegurança. AHCB, CC, Manual, XIII-4, ff. 79r, 87v; XIII-5, ff. 26r, 38r, 69v, 115r, 118r; XIII-6, ff. 3r, 42r, 43r, 66r, 129r, 130r; XIII-7, ff. 60v, 129r, 129v; XIII-8, ff. 16r, 16v, 33r.

${ }^{13}$ P. Orti, Renda i fiscalitat, pp. 173-185.

${ }^{14}$ La existencia de sociedades de carniceros con importantes capitales invertidos en ganado están documentadas ya en el siglo XIII. C. Batlle, Ll. Ramos, Contribució a la història, pp. 310-318.

15 R.A. Banegas, Camino de la ciudad, pp. 113-131.

${ }^{16}$ P. Orti, Renda i fiscalitat, pp. 173-185. 
Durante la primera mitad del siglo XV, a pesar de que se multiplican los contratos de assegurança ${ }^{17}$ y la documentación referente a los carniceros es más abundante, el número de carniceros que aparece en la documentación se ha reducido, además muchos de ellos están relacionados entre sí por vínculos de parentesco. La acumulación de capitales es clara en algunos carniceros, como es el caso de Antoni Lunes, que no aparece en la documentación hasta el año 1400, cuando firma el contrato de assegurança con el gobierno municipal ${ }^{18}$. Este carnicero, en 1427, en el capbreu de la Carnicería Mayor, declara poseer la propiedad útil de seis tablas en el interior de la carnicería y una en el exterior, pagando por ellas una renta de 8 libras, 13 sueldos y 4 dineros; por su parte Jaume Citjar - probablemente hijo del anterior- acumula cuatro tablas en la Carnicería Mayor y paga 8 libras, 11 sueldos y 8 dineros $^{19}$. La evolución en el mercado de la carne no es uniforme, junto a estos grandes carniceros, poseedores de varias tablas y de un volumen de negocio considerable, trabajan otros pequeños carniceros, los cuales se conforman con arrendar una sola tabla y cuyo volumen de negocio es mucho menor. En realidad los contratos de assegurança, que nos ofrecen una radiografía de los proveedores oficiales de la ciudad, muestran que el número de carniceros oscila durante la primera mitad del siglo XV entre los 17 de 1403 y los 8 de 1419; seguramente detrás de cada uno de estos carniceros se encontraría una compañía más o menos grande.

Esta estructura comercial dominada por los carniceros empieza a tambalearse en 1441, cuando el gobierno municipal de Barcelona le da el monopolio de la venta de carne en la ciudad a un ganadero a cambio de vender la carne a un precio inferior al ofertado por los carniceros de la ciudad. Esta situación se dará en diversas ocasiones y pone en evidencia un modelo completamente diferente de negocio. En este caso se trata también de una estructura comercial con una importante integración vertical, pero ahora dominada por ganaderos originarios de las zonas de producción -principalmente Lérida y su comarca- que contratan a los carniceros como meros asalariados ${ }^{20}$. Esta estructura no se llegará a consolidar, pero se convertirá en una amenaza para los carniceros y en una alternativa de abastecimiento para el gobierno municipal de Barcelona. La crisis que vive el negocio de la carnicería los años previos a la guerra civil catalana y el desastre de la propia guerra reforzarán durante la segunda mitad del siglo XV las divisiones entre los carniceros de la ciudad, dando la hegemonía en el negocio a un pequeño grupo de ellos. Una de las familias que sale más reforzada de la guerra es la familia Citjar; por ejemplo, Joan Citjar y su hijo, en 1477, aseguran siete tablas de carnicería y se comprometen a vender 54 carneros diarios ${ }^{21}$. El poder acumulado por esta familia de carniceros hace que en 1476 Joan Citjar se erija en portavoz de los carniceros frente al gobierno municipal y que el mismo consejo municipal denomine a los carniceros de manera despectiva en Citjar e sos sequassos ${ }^{22}$. La polarización eco-

${ }^{17}$ Las fuentes catalanas y valencianas utilizan la palabra assegurança, en Castilla las fuentes hablan de "obligado". En los dos casos se trata de un contrato firmado entre uno o más proveedores (que pueden ser los carniceros de la ciudad) y el gobierno de la ciudad, donde los proveedores se comprometen a vender carne durante todo el año a un precio estipulado y el gobierno municipal a cambio de su compromiso les asegura el monopolio del mercado. R.A. Banegas, Comer carne, pp. 329-355; P. Verdés, Administrar les pecúnies, pp. 268-275; J.A. Barrio, El abastecimiento y venta de carnes, pp. 257-278; J.A Bonachía, Abastecimiento urbano, pp. 85-161; M.A. Marín, Las carnicerías y el abastecimiento, pp. 51-99; A. Matilla, Abastecimiento de carne en Madrid, pp. 13-23.

${ }_{18}$ AHCB, CC, Llibre del Consell, vol. XXVIII, f. 12v.

${ }^{19}$ P. Orti, Renda i fiscalitat, pp. 173-185.

${ }^{20}$ AHCB, CC, Registre de deliberacions, II-2, f. 148v.

${ }^{21}$ AHCB, CC, Manual, XIII-21, f. 42v.

${ }^{22}$ AHCB, CC, Registre de deliberacions, II-23, f. 28v; AHCB, CC, Lletres closes, VI-27, f. 90v. 
nómica en el seno de los carniceros supone el abandono de una parte de los mismos, pero no la desaparición de los pequeños carniceros, que siguen existiendo hasta el final del siglo. Es el caso de Gabriel Montcada y Pere Rafael, dos pequeños carniceros que para sobrevivir han asociado sus negocios y entre los dos arriendan dos tablas de carnicería y cortan alrededor de 10 carneros diarios ${ }^{23}$. El manifiesto interés económico que genera el negocio de la carnicería, junto con el hueco que dejan los carniceros que no han resistido la crisis, permite que a finales del siglo XV aparezcan en el mercado de la carne barcelonés inversores ajenos al mundo de la carnicería. Se trata de ciudadanos barceloneses de diferentes categorías sociales, como por ejemplo un caballero de la Orden del Hospital, un doctor en leyes o un notario, que arriendan una o más tablas y se comprometen a abastecer de carne la ciudad, firmando junto a algunos carniceros los contratos de assegurança ${ }^{24}$. Naturalmente estos inversores contrataban carniceros y pastores para hacer todo el trabajo, ellos únicamente aportaban el capital necesario para que el proceso se llevara a cabo.

En Barcelona, por lo tanto, durante el siglo XIV, el negocio de la carnicería estuvo dominado por los carniceros, mientras que durante el siglo XV aparecen nuevos actores, a medida que una parte de los miembros más débiles del oficio sufren el impacto de las sucesivas crisis.

El modelo de la carnicería de Ruán y su evolución tiene muchos puntos de coincidencia con el de Barcelona, pero también destacadas divergencias. Normandía, a diferencia de Cataluña, es un territorio con excedente de ganado; de la península sale ganado que abastece a otras regiones como la Île de France ${ }^{25}$, la Picardía ${ }^{26}$ e incluso los Países Bajos ${ }^{27}$. La abundancia de ganado y la proximidad de los espacios de cría del mismo hace que la cadena comercial de la carne se estructure de una manera algo diferente a como se hacía en Barcelona. Para los carniceros ruaneses el principal lugar de venta de ganado destinado a carne se encontraba en Neubourg -población situada a unos $40 \mathrm{~km}$ al sur de la ciudad- en un mercado semanal que se realizaba los miércoles y donde compraban el ganado para toda la semana ${ }^{28}$. Los carniceros de la capital normanda no tenían que realizar largos viajes desde las zonas ganaderas hasta la ciudad con los rebaños destinados al matadero, sino que compraban los animales según las necesidades de cada semana, por tanto, la inversión económica debería de ser menor. A pesar de todo, las fuentes indican que los carniceros se tenían que asociar para afrontar el negocio, en este caso el problema no era el transporte, sino el precio de los animales. Concretamente en el norte de Francia la carnicería estaba basada en la carne de buey, mientras que en Cataluña se basaba en la de carnero ${ }^{29}$. Un buey graso destinado a carne es once veces más caro que un carnero graso; a pesar de que el beneficio que se extrae en carne, cuero y sebo es proporcional ${ }^{30}$, muchos carniceros son incapaces de afrontar este gasto en solitario. Como en Barcelona, entre los carniceros que trabajan en la ciudad hay importantes diferencias económicas que se fraguan a lo largo de los dos siglos. Al final del siglo XV la mayoría de los carniceros ruaneses tienen dificultades para afrontar el negocio en solitario por falta de capital, pero hay también una pequeña minoría de carniceros con capital suficiente para comprar gran-

\footnotetext{
${ }^{23}$ R.A. Banegas, C. Segovia, Problemes en l'entrada, pp. 121-142.

${ }^{24}$ AHCB, CC, Manual, XIII-21, f. 96v, XIII-22, f. 20.

${ }^{25}$ B. Descamps, De l'étable à l'étal, pp. 333-350.

${ }^{26}$ V. Doom, Une communauté de métier, pp. 117-146.

${ }^{27} \mathrm{R}$. Van Uytven, L'approvisionnement des villes, pp. 75-115.

${ }^{28}$ Ch.M. Robillard de Beaurepaire, Inventaire sommaire, p. 173.

${ }^{29}$ R.A. Banegas, Consumption of meat, pp. 63-86.

${ }^{30}$ ADSM, AMR, Chartrier 113-2 [11-10-1551].
} 
des cantidades de ganado directamente a los productores, destinando una parte a sus propias tablas y otra a las tablas de los carniceros con menos recursos económicos ${ }^{31}$. A pesar de la penuria documental han quedado testimonios de algunos de estos carniceros más poderosos. Por ejemplo, Martin Potier en 1480 vende varias casas por valor de 260 libras al monasterio de San $\mathrm{Ouen}^{32}$; a su poder económico se une la fuerte implantación de su familia en la corporación de carniceros viejos. Otro caso sería el de Jean Mercier, carnicero de la corporación de carniceros foráneos, el cual a finales del siglo XV ejerce como proveedor del monasterio de San Ouen ${ }^{33}$.

En la capital de Normandía el mercado de la carne durante los dos últimos siglos de la Edad Media siempre estuvo dominado por los carniceros; su número osciló según las circunstancias; en algunos momentos las autoridades consideraron que era insuficiente y se promovió la instalación de profesionales venidos de fuera, sin embargo, a finales del siglo XV y comienzos del XVI, la cantidad de carniceros que trabajaba en la ciudad había crecido muchísimo; el gobierno municipal calcula que en 1521 había alrededor de 238 carniceros ejerciendo en la ciudad, entre los cuales existían importantes desigualdades económicas ${ }^{34}$.

\section{LA INTERVENCIÓN INDIRECTA EN EL MERCADO DE LA CARNE: EL CASO DE RUÁN}

El mercado de la carne en Ruán se estructurará durante los siglos XIV y $\mathrm{XV}$ a partir de las corporaciones de oficio, que representarán a la profesión ante el poder municipal y real. A finales del siglo XV Ruán contaba con tres corporaciones de oficio de carniceros, tres corporaciones independientes que se regían por sus propios estatutos y elegían sus propios guardas para supervisar el trabajo de los miembros de la corporación. La existencia de tres corporaciones para un solo oficio es el resultado de un largo proceso, a través del cual se puede observar la política del municipio y la monarquía respecto al mercado de la carne.

La corporación de oficio de los carniceros viejos de Ruán nace, probablemente, durante el siglo XIII como una asociación de los carniceros que en esos momentos trabajaban en la ciudad y su objetivo era poner orden en el mercado de la carne. El desarrollo de la corporación a principios del siglo XIV les permite pedir la aprobación real de los estatutos en 1322. La función de la corporación era, por un lado, controlar el acceso al oficio y, por otro lado, controlar la calidad y salubridad de las carnes puestas a la venta. En los estatutos de 1497, los únicos que se han conservado, se establece que los maestros han de elegir ocho guardas y tres varletz -tres ayudantes- cuya función en un principio será inspeccionar toda la carne que se vende en la ciudad y descubrir los posibles fraudes. Estos guardias debían inspeccionar, pero no tenían ninguna capacidad sancionadora; cualquier falta debían comunicarla a las autoridades municipales -durante la época comunal- o reales -tras la Harelle- las cuales se encargaban de juzgar y sancionar la falta ${ }^{35}$. El hecho de no disponer de ninguno de los estatutos anteriores hace difícil saber si desde el principio la corporación contaba con la existencia de los guardias. Algunos estatutos de finales del siglo XIII muestran que en ciertos casos la inspección de la venta se dejaba de manera colegiada a todos los miembros de la corporación, quienes si veían alguna infracción debían

\footnotetext{
${ }^{31}$ ADSM, AMR, Registre de délibérations, A-10, ff. 365v-366r.

${ }^{32}$ ADSM, 14H-862 [04/03/1480].

${ }^{33}$ ADSM, 14H-99.

${ }^{34}$ ADSM, AMR, Registre de délibérations, A-11, ff. 317v-318r.

${ }^{35}$ ORF, vol. XX, París, 1840, pp. 621-626.
} 
comunicarla a la autoridad real, señorial o municipal. Éste es el caso de los estatutos de la corporación de carniceros de Sainte-Geneviève en París ${ }^{36}$, en otros casos, como en Amiens, desde principios del siglo XIV hay un grupo de maestros que supervisan el trabajo de sus compañeros ${ }^{37}$. Las corporaciones de carniceros, no solo en Ruán, sino en todo el norte de Francia, cumplían una importante función pública, la inspección de la higiene y la calidad de la carne. Tradicionalmente se ha defendido que la delegación de esta función pública en las corporaciones se hacía a cambio de otorgarles a sus miembros el monopolio sobre el mercado ${ }^{38}$, lo que entra en contradicción con la voluntad de los poderes públicos de evitar los monopolios para intentar impedir subidas artificiales de precios. De hecho, los poderes públicos tienen que buscar el difícil equilibrio entre control de la venta de carne y un mercado lo más libre posible para mantener la competencia y evitar una posible concertación de los precios ${ }^{39}$. Según Heather Swanson, la rígida estructura que se desprende de la lectura de los estatutos de las corporaciones de oficio muchas veces no se corresponde con una realidad económica igual de severa y esconde una economía mucho más dinámica ${ }^{40}$. En el caso de Ruán, hasta 1322 los carniceros no cuentan con unos estatutos oficiales aprobados por la autoridad y se regulan por la costumbre oral; a partir de 1322 la nueva normativa parece que otorga el derecho exclusivo a vender carne a los carniceros que trabajan en las cuatro carnicerías de la ciudad: Massacre, Saint-Ouen, Saint-Vivien y Saint$\mathrm{Maclou}^{41}$. Aunque no se especifica en los estatutos, probablemente durante los días de feria se permitiría vender carne a los carniceros forains, los carniceros que no residen en la ciudad y no pertenecen a la corporación, tal y como sucede en otros lugares de Normandía ${ }^{42}$. El derecho exclusivo de venta de carne que tenían los carniceros viejos, como mínimo durante los días ordinarios, se rompe 36 años después de la aprobación de sus estatutos. En 1358 el maire de la ciudad, ante la avalancha de refugiados que recibe Ruán del campo circundante a causa de la guerra que asola el ducado, decide permitir a los carniceros foráneos instalarse de manera permanente en la ciudad, autorizando que sacrifiquen animales y vendan carne en los alrededores de las puertas. $\mathrm{El}$ argumento principal de las autoridades municipales para concederles el permiso de venta es dar trabajo a los carniceros refugiados, evitando que caigan en la pobreza y la mendicidad. Tras estas justificaciones también se encuentra una razón menos altruista, bajar los precios de la carne:

Los víveres se encarecieron mucho en la ciudad, lo cual fue en gran perjuicio y acuerdo del común (...) y para evitar el encarecimiento de los víveres y vituallas se ha dado permiso y licencia que puedan vender los alimentos de dicho oficio buenos y leales ${ }^{43}$.

${ }^{36}$ R. De Lespinasse, Les métiers et corporations, p. 263.

${ }^{37} \mathrm{~V}$. Doom, Une communauté de métier, pp. 117-146.

${ }^{38}$ S. Ogilvie, Can We Rehabilitate the Guilds?, pp. 1-63.

${ }^{39}$ D. Wood, Medieval Economic Thought, pp. 141-142.

${ }^{40} \mathrm{H}$. Swanson, The illusion of economic structure, pp. 29-48.

${ }^{41}$ ORF, vol. XX, pp. 621-626.

${ }^{42}$ En los estatutos de la vecina población de Caudebec-en-Caux queda bien claro que los carniceros "de dehors et forains" pueden trabajar en la ciudad los días de mercado: "sans prejudice toutesfoiz des bouchers de dehors et forains autres que de ladite ville et banlieue qui ont droit et acoustumé de apporter vendre chars en ladite ville au jour de marché". ORF, vol. XIX, p. 563.

43 "les dictes vivres fuissent trop encheris en la dicte ville laquelle chose ault este en grant preiudice e assantement du commun (...) et pour eviter a la cherté des vivres et vituailles dessusdites avoir donné congé et lycence que il puissent vendre en ladicte ville des denrées dudit mestier bonnes et loyaulx". ADSM, AMR, Chartrier núm. 113-1 [22/11/1358]. 
Por tanto, el gobierno municipal considera que para bajar los precios es necesario aumentar la competencia en la ciudad y evitar que un grupo de carniceros tenga la exclusividad en el negocio. Los nuevos carniceros que se instalan en la ciudad serán inspeccionados por los guardias de la corporación de los carniceros viejos para evitar fraudes en la venta de carne, pero en sí no forman ninguna corporación y trabajan por libre.

Naturalmente, los carniceros que forman parte de la corporación de oficio ven con hostilidad la intromisión de nuevos competidores en un mercado que ellos consideran suyo. La falta de organización, la multiplicación de las tablas de carnicería por la ciudad, juntamente con la fuerte rivalidad entre la corporación de los carniceros viejos y los nuevos carniceros hará que la corporación de carniceros pida al rey un ordenamiento de la carnicería en la ciudad. El rey, en 1390, responderá a la demanda ordenando que los carniceros foráneos se instalen en un mercado cubierto propiedad de la monarquía: las Halles du vieux marchét4. Con esta iniciativa los carniceros viejos -con la aquiescencia de las autoridades públicas- quieren concentrar la venta de carne que realizan los carniceros foráneos, para mejorar la supervisión de la venta de carne y aumentar el control de la corporación sobre los nuevos carniceros. Por su parte, a las nuevas autoridades reales que gobiernan la ciudad de Ruán les interesa mantener el equilibrio entre una carnicería ordenada y supervisada, y un oficio dividido y en competencia.

En 1382 Ruán se subleva contra la alta fiscalidad real, la revuelta, llamada de la "Harelle", fue aplastada por la monarquía y la represión sobre la ciudad fue terrible. El rey abolió el gobierno municipal, aumentó la presión fiscal e impuso una fuerte multa; como resultado, una parte importante de la población huyó para escapar a la presión fiscal y a la multa, sumiendo a la ciudad en una profunda depresión ${ }^{45}$. Para paliar la despoblación, el rey Carlos VI concede en 1408 a todos los carniceros que lleguen de fuera de la ciudad y que hayan ejercido como maestros en otra ciudad donde la carnicería esté reglamentada permiso para ejercer en Ruán como maestros en igualdad de condiciones con los miembros de la corporación ${ }^{46}$, siempre y cuando paguen los derechos exigidos, se subordinen a la normativa de la ciudad y ejerzan en el espacio reservado para los carniceros foráneos ${ }^{47}$. En este caso la corporación de carniceros se ve forzada a aceptar esta nueva normativa por la grave situación que afronta la ciudad y por el hecho que la normativa específica sobre los carniceros se enmarca en una más amplia que permite la entrada de foráneos en todas las corporaciones de oficio de la ciudad. Solo unas décadas después, en 1432, el bailli aprueba unos supuestos estatutos perdidos del mestier et marchandise de la boucherie ès halles du Vieil-Marché et à la porte Beauvoisine, con los que se consolida definitivamente la presencia de los carniceros foráneos en la ciudad. La monarquía anglo-francesa de

${ }^{44}$ ADSM, AMR, Chartrier núm. 113-1 [06/03/1390].

45 Tras la revuelta de la Harelle de 1382 la represión real sobre la ciudad fue brutal, tras el arresto y castigo de los instigadores siguió una multa a toda la ciudad de 60.000 libras a pagar en trece meses, la presión fiscal que siguió a la imposición de la multa hizo que la ciudad se despoblara. El rey, además, suprimió el gobierno municipal de Ruán que databa del siglo XII y que había servido de modelo para numerosas ciudades del oeste y el sudoeste de Francia. Con la abrogación de la carta municipal el cargo de maire desaparece y el gobierno municipal pasa a manos de un oficial real: el bailli. El bailli se rodeará de seis consejeros y de una asamblea extensa, la cual tenía que ratificar las ordenanzas reales, votar los impuestos y opinar sobre los asuntos financieros y patrimoniales de la ciudad; este consejo, a partir de la ocupación inglesa, recibió el nombre de Conseil des Ving-Quatre (consejo de los veinticuatro). M. Mollat, Histoire de Rouen, pp. 119-124.

46 "Ville de Loy ou autre ville où il eust ordonnance de mestier". ORF, vol. IX, p. 412.

${ }^{47}$ ADSM, AMR, Vidimus de Chartres, U-2, f. 38r; ORF, vol. IX, p. 412. 
Enrique VI aprueba los nuevos estatutos por dos razones, la primera es consolidar definitivamente a los carniceros foráneos en la ciudad y crear una corporación rival a la corporación de los carniceros viejos, la segunda es aprovechar el beneficio económico que obtiene la monarquía del encuadramiento de los carniceros foráneos en una corporación, ya que a partir de ahora para poder ejercer su oficio tendrán que pagar unos derechos de entrada, de los cuales una parte considerable irá a parar a las arcas reales $^{48}$.

Durante los años 30, la ofensiva francesa sobre las posesiones de la doble corona extiende la guerra hasta las puertas de Ruán y otra vez la ciudad se llena de refugiados. En 1436, como sucedió en el siglo anterior, el bailli de la ciudad aprueba que los carniceros que se han refugiado en Ruán procedentes de otras ciudades, como Chartres, Abbeville o Dieppe, puedan ejercer en el exterior de las puertas de la ciudad, bajo la supervisión de los guardas de las dos corporaciones de carniceros ${ }^{49}$. Por lo tanto, una vez más, al poco tiempo de conceder el monopolio del mercado de la carne y del acceso al oficio a las dos corporaciones de carniceros de la ciudad, la propia monarquía lo rompe dando permiso para trabajar a los carniceros refugiados sin necesidad de que formen parte de ninguna corporación. La oposición de las dos corporaciones a la instalación de los recién llegados es feroz; en 1446, los carniceros argumentan que, tras la firma en 1444 de la tregua de Tours, no tiene sentido consentir el trabajo de carniceros no encuadrados en una corporación, porque en su opinión había demasiados carniceros en la ciudad y no había suficiente negocio para todos. En respuesta a la demanda, el bailli, formalmente, cesa el permiso de trabajo al conjunto de los carniceros instalados en las puertas de la ciudad y que no forman parte de las dos corporaciones; esta suspensión, el mismo bailli la atenúa con la concesión de permisos individuales a los carniceros refugiados que trabajan en feudos del rey y que, por tanto, pagan rentas a la monarquía ${ }^{50}$. A pesar de que solo se ha conservado uno de estos permisos, la aprobación en 1487 de los estatutos de la corporación de los carniceros de los suburbios y de las puertas de la ciudad muestra que los carniceros de las puertas siguieron trabajando a pesar de la prohibición gracias a permisos anuales, los cuales les obligaban a trabajar en una extrema precariedad, ya que no se atrevían a hacer inversiones por miedo a que al año siguiente les rescindieran el permiso $^{51}$.

En 1446 aparece un elemento nuevo en el conflicto que enfrenta a los distintos grupos de carniceros de la ciudad y al conjunto del oficio con el gobierno municipal: el supuesto exceso de carniceros que padece Ruán. El control del número de trabajadores de un mismo oficio en una ciudad es una de las tareas a través de las cuales las corporaciones de oficio justificaban su existencia, ya que ellas se encargaban de controlar el acceso a una determinada profesión, asegurando que sus miembros tuviesen un nivel técnico adecuado y que hubiese un mercado suficiente para llevar una vida digna según su estatus ${ }^{52}$. Este argumento será criticado en el siglo XVIII por Adam Smith, quien considerará que la restricción del acceso a un determinado oficio por las corporaciones impide que se produzca un verdadero equilibrio entre oferta y demanda en el mercado

\footnotetext{
${ }^{48}$ Concretamente el aprendiz para entrar a trabajar con un maestro debe pagar una fianza de 10 libras, de las cuales 5 son para el rey y las otras 5 se las debe administrar el maestro para los gastos del aprendiz. Para ser maestro de pleno derecho de la corporación, los aspirantes deben pagar una hanse de 60 sueldos, de los cuales 40 los cobra el rey y los otros 20 la corporación. ORF, vol. XX, pp. 39-45.

${ }^{49}$ ADSM, AMR, Chartrier $113-1^{\circ}[17 / 10 / 1436]$.

${ }^{50}$ ADSM, AMR, Chartrier 113-1º [12/04/1446].

${ }^{51}$ ORF, vol. XX, pp. 48-51.

52 D. Wood, Medieval Economic Thought, pp. 141-142.
} 
de trabajo y, a la vez, al restringir el mercado a unos pocos elementos, éstos pueden manipular los precios a su antojo ${ }^{53}$. En el caso de Ruán, se ha podido observar que las corporaciones de oficio de los carniceros fueron incapaces de cerrar el mercado de trabajo de la carnicería, ya que se encontraron con la oposición de las autoridades municipales y reales, que se apoyaron en el conflicto bélico que asoló Normandía durante los dos siglos para no ceder el control del mercado de trabajo de la carnicería a las corporaciones. Gracias a que el mercado de trabajo había permanecido abierto durante este tiempo, a principios del siglo XVI había en Ruán 238 carniceros para una población que ronda los 50.000 habitantes $^{54}$, una proporción de uno por cada 210 habitantes, una cifra que no difiere demasiado de la que encontró Philippe Wolff en Toulouse o Louis Stouff en las ciudades provenzales ${ }^{55}$. Ya se ha visto que uno de los argumentos de las dos corporaciones de carniceros para pedir que se rescindiera el permiso de venta a los carniceros de las puertas de la ciudad era que había demasiados carniceros y no había suficiente mercado para todos. Las autoridades municipales no compartían la opinión de los carniceros; así, en 1446 de una manera encubierta habían dado un paso para consolidar a los carniceros de las puertas y en la primavera del año siguiente, ante la carestía de carne que padece la ciudad, les preguntan a los carniceros por qué los aprendices no llegan a maestros y no aumenta el número de carniceros en la ciudad ${ }^{56}$.

A lo largo de los dos siglos, el consejo municipal de Ruán y la monarquía habían buscado mantener abastecido el mercado de carne de la ciudad con productos a buen precio pemitiendo la competencia e intentando evitar que los carniceros de la ciudad cerraran el mercado y crearan un oligopolio con capacidad para concertar los precios. Sin embargo, a principios del siglo XVI parece que han fracasado en su empeño y dan un giro de $180^{\circ}$ en su política; si en 1447 se preocupan porque los aprendices no llegan a maestros, en 1521 dicen que hay demasiados carniceros en la ciudad y que el exceso de carniceros, junto con el hecho de que se creen sociedades de hasta once carniceros para comprar un solo buey, está encareciendo la carne ${ }^{57}$. La lógica de las autoridades municipales de Ruán se ancla profundamente en el pensamiento económico medieval, según el cual el precio de los productos se basa en la oferta, en la demanda y en los costes de la producción, incluyendo los gastos en salarios ${ }^{58}$. En una sociedad como la bajomedieval, fuertemente jerarquizada y con una lenta movilidad social, no es fácil cambiar de oficio ${ }^{59}$. Según la concepción de la economía que tienen los miembros del consejo municipal, el mercado de trabajo tendrá dificultades para regularse por sí solo expulsando a aquellos que se arruinen por falta de mercado; así, en su opinión, el exceso de carniceros repercutirá en los precios de la carne, ya que todos cargarán su parte de salario sobre el precio final del producto. Otro problema es que, a pesar del gran número de carniceros que hay en la ciudad, el peligro de aparición de un oligopolio con capacidad para manipular los precios no desaparece; en 1516 los consejeros de la ciudad se quejan de que hay cinco o seis grandes mercaderes carniceros que van por el país intentando comprar el ganado a mejor precio para, por un lado, venderlo en sus propias tablas con mayor beneficio y, por otro, revenderlo al resto de los carniceros de la ciudad ${ }^{60}$.

${ }^{53}$ A. Smith, La riqueza de las naciones, pp. 105-106.

${ }^{54}$ P. Chaunu, R. Gascon, Histoire économique, vol. I, p. 397.

55 Ph. Wolff, Les bouchers de Toulouse, pp. 375-393; L. Stouff, La viande, pp. 1431-1437.

${ }^{56}$ AMR, Registre de délibérations, A-7, f. 3r-v.

${ }^{57}$ AMR, Registre de délibérations, A-11, ff. 317v-318.

${ }^{58}$ D. Wood, Medieval Economic Thought, pp. 133-158.

${ }^{59}$ Sobre este tema ver: D. Herlihy, Three patterns, pp. 623-647; S. Carocci, La mobilità sociale nel medioevo.

${ }^{60}$ ADSM, AMR, Registre de délibérations, A-10, ff. 365v-366. 
Durante los siglos XIV y XV las autoridades municipales de Ruán habían actuado de una manera muy indirecta en el mercado de la carne de la ciudad. Su política se limitaba a intentar evitar que la corporación y luego corporaciones de carniceros cerraran el mercado y crearan un oligopolio con capacidad para manipular los precios. A finales del siglo XV y sobre todo desde principios del siglo XVI la política de las autoridades cambia, el consejo municipal, impelido por el importante aumento de los precios $^{61}$, inicia una política muy activa de reformas en la ciudad entre las cuales se encuentra mejorar el suministro de carne. Este cambio de política queda bien reflejado en el conflicto que mantiene a finales del siglo XV la corporación de los carniceros viejos de Ruán con el rey y el bailli de la ciudad sobre la capacidad de este último para modificar los estatutos de los carniceros sin el consentimiento de la corporación ${ }^{62}$. El rey está intentando imponer su soberanía haciendo valer su capacidad para legislar sin necesidad de pedir consentimiento o compartir esta prerrogativa con nadie ${ }^{63}$.

Esta capacidad legisladora quedará patente en el programa de reformas del mercado de la carne de Ruán, el cual quedará definitivamente establecido en 1524 , pero no se pondrá en práctica hasta 1551 . Los consejeros, esta vez además de considerar que hay demasiados carniceros en la ciudad, consideran que se ha creado un grupo de grandes mercaderes carniceros que compra el ganado antes de que llegue al mercado y luego lo revende ${ }^{64}$, una práctica que el pensamiento económico medieval consideraba que encarecía de manera artificial el producto, ya que el intermediario saca un beneficio sin aportar ningún valor a la mercancía a través del proceso de transformación o transporte ${ }^{65}$. Para mejorar el mercado de carne de la ciudad se decide: limitar el número de carniceros de la ciudad a 80, prohibir que un carnicero pueda vender carne y ganado a la vez -se les obliga a elegir una de las dos profesiones y renunciar a la otra- también se prohíbe ir por delante de los mercaderes para comprar el ganado antes de que llegue a la feria y revenderlo luego más caro, finalmente, la carne se ha de vender a peso para que el municipio pueda controlar la fluctuación de los precios y en caso necesario pueda establecer precios máximos ${ }^{66}$. El problema de la venta a peso demuestra el limitado margen de maniobra que tenía el consejo ruanés para controlar el precio de la carne en la ciudad. En Ruán, como en todo el norte de Francia, la carne se vendía a estima y no a peso, el precio se fijaba por el tipo de pieza y por el tamaño de la misma; este método dificultaba a las autoridades y a los clientes conocer la evolución de los precios. La confusión que genera la venta a estima la retrata muy bien el autor del Mesnagier de París cuando dice yo no sé exactamente cómo los burgueses hacen sus cuentas con los carniceros, cómo miden las proporciones justas. Un buen buey puede costar 20 libras, mientras que otro no cuesta más de $12^{67}$. Para evitar estas fluctuaciones de los precios y ejercer un control más estricto de la venta, en 1420, en un momento de encarecimiento de la carne a causa de la guerra, se obligó a los carniceros vender a peso ${ }^{68}$. El resultado fue desastroso, el fraude masivo que hacían los carniceros y la falta de herramientas de la autoridad para controlarlo

${ }^{61} \mathrm{Ph}$. Hamon, Les renaissances, pp. 123-131.

62 AMR, Chartrier núm. 113-1 [26/02/1500]; ADSM, 2 E-1-228.

${ }^{63}$ R. Beauthier, Droit et genèse de l'État, pp. 287-296.

${ }^{64}$ ADSM, AMR, Registre de délibérations, A-12, ff. 176v-180.

65 D. Wood, Medieval Economic Thought, pp. 133-158.

${ }^{66}$ C.M. Robillard de Beaurepaire, Inventaire sommaire, p. 173.

67 "si ne scay comment la taille des bourgoiz se peut proporcionner en compte justement avec les bouchiers. Car le bon beuf couste XX. livres ou l'autre ne couste que XII”. G.E. Brereton, J.M. Ferrier, Le Mesnagier de Paris, p. 600.

${ }^{68}$ P. Cochon, Chronique Normande, p. 346. 
hizo que al año siguiente se derogara la ordenanza y los carniceros volvieran a vender a estima hasta el siglo XVI. El cambio de vender a estima a vender a peso no es fácil, en la documentación ruanesa de principios del siglo XVI no hemos encontrado testimonios de protestas o problemas cuando se realizó de manera definitiva el cambio, sin embargo en otras ciudades donde se implantó la venta a peso de la carne en esta misma época, como es el caso de Londres, los problemas y conflictos que generó esta medida tardaron años en resolverse ${ }^{69}$.

A lo largo del capítulo se ha podido comprobar cómo el único mecanismo que tuvo el gobierno municipal de Ruán para mantener la ciudad abastecida de carne a precios asequibles fue evitar que se cerrara el mercado. Así, durante los dos siglos se permitió de manera regular la entrada de elementos nuevos procedentes del exterior para que compitieran con los carniceros ya establecidos en la ciudad, con la intención de evitar que un grupo reducido de carniceros acabara monopolizando el mercado de la ciudad y concertando los precios. No se ha de descartar, a la hora de analizar la voluntad del poder municipal y real de dar entrada a nuevos elementos en el mercado de la carne, razones de carácter político. Michel Mollat subraya en su monografía sobre la Historia de Ruán que los principales instigadores de la revuelta de la Harelle fueron las corporaciones de los carniceros y de los pañeros ${ }^{70}$. Curiosamente, en los años que siguieron a la revuelta, el rey y el nuevo consejo municipal, consolidan tanto a los carniceros foráneos como a los pañeros foráneos en la ciudad, con la oposición de las respectivas corporaciones de oficio. El intento de la monarquía durante el siglo XIV y XV de contrarrestar el poder creciente de ciertas corporaciones profesionales, entre las que destacan las de los carniceros, está muy bien documentado en otras ciudades del norte de Francia ${ }^{71}$.

El intento fracasado de imponer la venta de carne a peso en 1420 demuestra hasta qué punto el consejo municipal y la monarquía eran incapaces de intervenir de una manera más activa en el mercado de la carne para ordenarlo. No fue hasta principios del siglo XVI, con la llegada de la paz y la definitiva consolidación del poder real, cuando se inició una campaña de reformas para controlar de una manera más directa el mercado, dejando, sin embargo, una enorme libertad a las corporaciones y a los propios carniceros.

\section{LA INTERVENCIÓN DIRECTA EN EL MERCADO DE LA CARNE: EL CASO DE BARCELONA}

En la ciudad de Barcelona, a principios del siglo XIV los carniceros no formaban ningún tipo de corporación o asociación de tipo laboral, no será hasta 1380 cuando el rey Pedro el Ceremonioso conceda los primeros estatutos a la cofradía de los carniceros. Las ordenanzas de esta cofradía no tienen nada que ver con los estatutos de las corporaciones de oficio de Ruán, son unos estatutos de carácter puramente religioso y los únicos elementos con relación al oficio son aquellos que hacen referencia al trabajo durante los días de abstinencia de carne ${ }^{72}$. En el caso de Barcelona, a diferencia de lo que sucedía en Ruán, las ordenanzas que regulan el mercado de la carnicería las crea directamente el consejo municipal sin necesidad de tener el consen-

${ }^{69} \mathrm{Ph} . \mathrm{E}$. Jones, The butchers of London, pp. 106-120.

${ }^{70}$ M. Mollat, Histoire de Rouen, p. 120.

${ }^{71}$ B. Descamps, La destruction, pp. 109-118; J.A. Durbec, La grande boucherie de Paris, pp. 71-73.

${ }^{72}$ M. Bofarull, Gremios y cofradías, pp. 178-187. 
timiento de los carniceros; por otra parte, la inspección de las carnicerías hasta 1339 la realizaban los oficiales reales -el veguer y el batlle- y a partir de 1339 la realizará el mostassaf, un oficial específicamente dedicado a controlar el mercado y el urbanismo de la ciudad ${ }^{73}$. La imposibilidad de los carniceros de justificar su asociación como un elemento imprescindible para la mejora de la venta de carne, tal y como lo hicieron sus colegas de Ruán, sin duda ralentizó la formación de la corporación y provocó que tuviera una estructura muy diferente a la de sus homólogos ruaneses ${ }^{74}$.

Barcelona, fruto de su propia tradición legislativa y política, logró tener en el siglo XIV plena potestad para legislar en materia de mercado, además en el caso de la carne, al tratarse de un monopolio real, el control de las licencias para abrir nuevas carnicerías estaba en manos del rey y el control de la venta en las del municipio ${ }^{75}$. En conjunto, la capacidad de intervención en el comercio de carne de las autoridades públicas en la capital catalana fue mucho más intensa y directa que en la ciudad de Ruán ${ }^{76}$. En Barcelona, ya a principios del siglo XIV, la carne se vendía a peso y su precio máximo lo marcaba el consejo municipal. Los precios máximos se establecen por tipo de animal y no por pieza y a pesar de que, en un principio, el precio máximo legal se establece a partir del conocimiento que tienen las autoridades de los precios reales del mercado secundum aestimationem fori occurenti s $^{77}$, su escasa flexibilidad para adaptarlos, por un lado a las diferentes calidades en las piezas de carne y por otro, a las fluctuaciones del mercado, generará problemas especialmente en contextos inflacionarios. Un ejemplo de estos problemas lo encontramos durante la segunda mitad del siglo XIV, cuando en un momento de fuerte subida de los precios, el gobierno municipal intenta contenerlos fijando los precios máximos legales de la carne por debajo de los del mercado ${ }^{78}$. El resultado de esta política será que la ciudad tendrá problemas de abastecimiento de carne. Cuando las dificultades de suministro empiecen, las autoridades obligarán a los carniceros a surtir de carne sus tablas si no quieren que se les expropie el ganado. Estas medidas no harán sino agravar el problema; la primera vez que el consejo obligará a los carniceros a abastecer de carne la ciudad porque hay gran carestía de carnes será en $1366^{79}$, pero la ordenanza se repetirá en $1367,1368,1371,1378,1380,1387$ y $1389^{80}$.

La inoperatividad de las medidas de coacción destinadas a forzar a los carniceros a ofertar carne obligarán al consejo municipal a buscar nuevas fórmulas para

${ }^{73}$ C. Batlle, Vida i institucions polítiques, p. 275; J. Lalinde, La jurisdiccón real inferior, pp. 165-166, 171; J. Comellas, El mercat barceloní, pp. 95-96.

${ }^{74}$ En 1478 se establece que los maiorals o prohomens dels dits carnicers juren ante el mostassaf denunciar los fraudes cometidos en el ejercicio de la carnicería, ya que a causa de la complejidad del trabajo muchos fraudes no eran detectados directamente por el mostassaf y sus pesadores. Por tanto, a finales del siglo XV los representantes de la cofradía de carniceros se convierten en auxiliares del mostassaf y colaboran con él en la inspección del comercio de carne. AHCB, CC, Ordinacions especials, vol. X, f. 300v.

75 P. Ortí, Renda i fiscalitat, pp. 196-199.

${ }^{76}$ M. Bajet, Policia de mercat, pp. 121-143.

77 San Bernardino de Siena, De evangelio aeterno, sermón 35, art. 2, cap. 2; sermón 33, art. 2, cap. 7, part. 2, vers. 5. Citado por R. de Roover, The Concept of the Just Price, p. 423.

${ }^{78}$ Entre 1350 y 1372 los precios máximos de la carne, sin contar los impuestos, habían subido un $87,5 \%$, aun así, los problemas de abastecimiento que padeció la ciudad demuestran que los precios máximos estaban por debajo de los precios reales del mercado. R.A. Banegas, L'aprovisionament, vol II, p. 456.

79 "Per bé de la cosa pública de la ciutat de Barchinona en la qual ha gran minve de carns" AHCB, CC, Llibre del Consell, vol. XXIII, f. 34.

${ }^{80}$ AHCB, CC, Llibre del Consell, vol. XXIII, f. 73v; vol. XXIII, f. 80v; AHCB, CC, Ordinacions especials, V-2, f. 70v; V-4, ff. 113r-114; V-7, ff. 25r, 26r, 66r, 91r, 102r; V-8, f. 13v. 
mantener abastecida la ciudad al precio más bajo posible. El 24 de marzo de 1400 se firma una assegurança, un contrato que ya se había experimentado de manera esporádica durante el siglo XIV sin que tuviera continuidad ${ }^{81}$, a partir de 1400 las assegurances se firman anualmente, en estos contratos los carniceros se comprometen a mantener abastecidas sus tablas de carne durante todo el día, todos los días carnales, de Pascua hasta Carnaval, si no deben pagar una multa. Según pasan los años los contratos se van haciendo más complejos, poco a poco los carniceros pasan a concretar el número de animales que sacrificarán cada día, el número de tablas que aseguran, etc. ${ }^{82}$

En el año 1400, la firma de la assegurança llega tras una dura negociación. Los carniceros pedían para aceptar el contrato de abastecimiento la eliminación del impuesto al consumo sobre la casquería, que el municipio había establecido el año anterior ${ }^{83}$. El consejo municipal se niega a suprimir dicho impuesto, pero les concede a los carniceros subir el precio de todas las carnes 1 dinero a la vez que les amenaza con construir nuevas tablas de carnicería en la ciudad y concedérselas a carniceros foráneos si no aceptan las condiciones de venta propuestas por el municipio ${ }^{84}$. Esta negociación entre los carniceros y el gobierno municipal para fijar los precios y las cuotas de venta se repetirá anualmente y será siempre muy tensa, ya que los carniceros amenazan a las autoridades con dejar de servir carne si no se atiende a sus demandas y el municipio con buscar proveedores fuera de la ciudad si los carniceros no aceptan sus condiciones.

La tensión en la negociación está justificada, ya que está en juego el buen abastecimiento de carne y la solvencia económica del municipio, no se ha de olvidar que el impuesto sobre el consumo de carne era uno de los principales recursos económicos de la ciudad ${ }^{85}$. Los contratos de assegurança son muy rígidos ya que marcan un precio único de la libra de carne para todo el año, sin tener en cuenta que los precios del ganado o el coste del traslado pueden variar por múltiples circunstancias. En 1438, por ejemplo, los carniceros piden una subida del precio de la carne durante la cuaresma a causa de la subida de los derechos de paso en la frontera de Aragón ${ }^{86}$; en julio de 1484, los carniceros dejan de vender carne a pesar de haber firmado la assegurança durante el mes de abril, en este caso argumentan que la fuerte sequía que asola el país y el inicio de la guerra entre el rey y el conde de Pallars han encarecido el ganado y no pueden mantener el negocio si siguen vendiendo al precio que habían pactado con el consejo municipal en primavera ${ }^{87}$. Para salvar este problema, en circunstancias especiales y normalmente después de una fuerte presión por parte de los carniceros, el consejo decide imponer dos precios, un precio más bajo para los meses de primavera y verano y un precio más alto para los meses de otoño e invierno. Por ejemplo, en 1435 se decide que durante cinco meses - de abril a agosto- se vendería la libra de carnero a 15 dineros y los otros cinco meses -de septiembre a enero- a 16 dineros $^{88}$; de la misma manera, en 1455, tras una fuerte crisis de abastecimiento, el gobierno munici-

${ }^{81}$ Se han documentado dos contratos anteriores, concretamente en los años 1348 y 1349 . AHCB, CC, Manual, XIII-8, ff. 16r-33r.

${ }^{82}$ C. Carrère, Barcelona, centre econòmic, vol I, pp. 319-322.

${ }^{83}$ AHCB, CC, Llibre del Consell, vol. XXVIII, f. 12v.

${ }^{84}$ AHCB, CC, Llibre del Consell, vol. XXVIII, ff. 7v-12v.

${ }^{85}$ Como demuestra Pere Orti, en la segunda mitad del siglo XIV, los impuestos del vino y de la carne eran los más rentables de entre los que recaudaba el gobierno municipal. P. Orti, Renda i fiscalitat, cuadro 92, pp. 565-566.

${ }^{86}$ AHCB, CC, Registre de deliberacions, II-2, ff. 18v-19r.

${ }^{87} \mathrm{AHCB}, \mathrm{CC}$, Registre de deliberacions, II-27, f. 67v.

${ }^{88}$ AHCB, CC, Registre de deliberacions, II-1, f. 88. 
pal, convencido de la imposibilidad de los carniceros de seguir vendiendo al precio acordado en la assegurança, decide subir el precio del carnero un dinero a partir del 1 de noviembre y hasta carnaval ${ }^{89}$.

Las negociaciones entre carniceros y el consejo municipal para la firma de las asseguranças son cada vez más duras, por eso con el tiempo el consejo municipal va buscando nuevos recursos para forzar el acuerdo y mantener bajo el precio de la carne. En marzo de 1427 solo dos de los carniceros más ricos firman el contrato de assegurança; los carniceros temen no poder hacer frente a los gastos con los precios establecidos por el gobierno municipal y no se atreven a firmar; en abril, el consejo decide conceder a los carniceros que firmen el contrato un préstamo sin interés para que puedan hacer frente a los gastos de compra de ganado y su traslado hasta la ciudad, concretamente presta 1.100 libras a una sociedad formada por un carnicero y un pescadero que se comprometen a poner a la venta 40 carneros diarios en dos tablas ${ }^{90}$. En 1441 el consejo municipal ofrece 4.000 florines de préstamo y una subvención de 50 florines a un ganadero que se compromete a cortar 120 carneros diarios en cuatro tablas de carnicería a un precio inferior al que ofrecían los carniceros ${ }^{91}$. Los préstamos sin interés se utilizarán de manera habitual durante todo el siglo como un recurso para conseguir el compromiso de abastecimiento por parte de los carniceros de la ciudad o de proveedores externos. No siempre los incentivos logran el ansiado acuerdo de abastecimiento y, cuando esto sucede, las autoridades no dudan en coaccionar a los carniceros con todas las herramientas que tienen a su alcance. En 1434, por ejemplo, los carniceros se niegan a firmar el contrato de assegurança si no se sube el precio del carnero un dinero; el consejo municipal les ofrece un préstamo sin interés, pero los carniceros consideran que no es suficiente, quieren la subida del precio de la carne. Ante la negativa de los carniceros a firmar, el consejo decide encarcelar a unos cuantos con cadenas en los cuellos y grilletes en las piernas, pero a pesar de la presión, los carniceros no ceden y finalmente el consejo se ve forzado a subir el precio de la carne durante la mitad del año ${ }^{92}$. En 1455, tras la firma de un contrato con precios muy ajustados durante el mes de marzo, en septiembre la ciudad está desabastecida de carne; para presionar a los carniceros el consejo decide encarcelarlos y enviar al mostassaf a los corrales para incautarse de los carneros de los carniceros, sacrificarlos, cortarlos y ponerlos a la venta; pero, para desespero del gobierno municipal, el mostassaf no encuentra suficientes carneros y el consejo se ve forzado a renegociar el precio de la carne $^{93}$.

En las negociaciones para la firma de la assegurança el consejo municipal actúa de manera unida a través de un representante de la institución; por su parte, los carniceros contaron en escasas ocasiones con un portavoz del oficio que actuara en nombre de todos ante el gobierno de la ciudad. Por eso, a pesar de que en numerosas ocasiones lograron mantener de manera firme una postura unitaria frente a las proposiciones del municipio, en otras, afloraron las divisiones. De hecho, hubo negociaciones en las que, mientras unos carniceros se negaban a firmar, otros aceptaban las condiciones del consejo a cambio de un trato de favor. Seguramente, disponer de una cofradía, de la cual formaban parte un grupo importante de carniceros de la ciudad,

${ }^{89}$ AHCB, CC, Registre de deliberacions, II-9, f. 198v.

${ }^{90}$ AHCB, Notularum, XIV-2, f. 82v.

${ }^{91}$ AHCB, CC, Registre de deliberacions, II-2, f. 148v. f. $88 \mathrm{r}$

92 "ab cadenes als colls e grillons en les cames". AHCB, CC, Registre de deliberacions, II-1,

${ }^{93}$ AHCB, CC, Registre de deliberacions, II-9, f. $183 \mathrm{v}$. 
facilitó una cierta cohesión dentro del oficio ${ }^{94}$, pero en ningún momento evitó que en ocasiones la competencia y las rivalidades entre los carniceros alcanzaran un alto grado de virulencia. En 1449, por ejemplo, un grupo de carniceros se queja ante el consejo municipal porque hay carniceros que venden la libra de carnero por debajo del precio firmado en el contrato de assegurança, llevándose a los clientes y arruinando a aquellos carniceros que no pueden bajar más los precios. El consejo, que normalmente favorece a aquellos que venden a los precios más bajos, ahora teme que la ruina de una parte importante de los carniceros de la ciudad provoque que un grupo pequeño de carniceros pueda acaparar todo el negocio, lo que podría generar problemas de abastecimiento en el futuro. El miedo a que un pequeño grupo de carniceros pueda acaparar todo el mercado hace que, por primera vez, se imponga que no se pueda vender carne por debajo del precio acordado en la assegurança ${ }^{95}$.

En definitiva, el negocio de la carnicería en Barcelona estuvo fuertemente controlado por el gobierno municipal, el cual intervino de una manera muy activa en todos los aspectos del proceso comercial de la carne: legislando las condiciones de venta, fijando los precios, dando préstamos y subvenciones a los carniceros de la ciudad o a comerciantes foráneos, concediendo monopolios o rompiéndolos, etc. En cambio, los carniceros, a diferencia de lo que sucedía en Ruán, tenían una escasa estructura organizativa y muy poca cohesión interna. De hecho, la corporación de oficio se forma muy lentamente a lo largo de los siglos XIV y XV, a medida que sus prohombres van tomando el papel de auxiliares del mostassaf y representantes del oficio ante las autoridades municipales ${ }^{96}$.

\section{CONCLUSIONES}

A la hora de regular el mercado de la carne, tanto en Barcelona como en Ruán, las autoridades municipales tenían el mismo objetivo: ofrecer a la población carne segura a buen precio, pero los métodos para lograr ese objetivo difieren de una ciudad a otra. Mientras en Barcelona las autoridades municipales, dotadas de plena capacidad legislativa y ejecutiva, crean una compleja legislación para regular el mercado de la carne y utilizan al mostassaf como una herramienta eficaz para aplicarla, en Ruán, la estructuración municipal dificulta una intervención tan directa, ya que la legislación la crean el municipio o el rey conjuntamente con las corporaciones de carniceros -que forman parte del entramado institucional de la ciudad-y son los mismos carniceros los encargados de inspeccionar su trabajo a través de las corporaciones de oficio. Ante esta situación, tanto el municipio como el rey actúan de manera indirecta, supervisando el buen funcionamiento del entramado corporativo e incentivando la entrada de elementos externos para favorecer la competencia. En Ruán, como en el resto

94 Después de la guerra civil los carniceros se presentarán más unidos y estará representados por Joan Citjar, el carnicero más rico y poderoso de la ciudad, el cual aparece como interlocutor de los carniceros en las negociaciones de 1476, 1479 y 1482. AHCB, CC, lletres closes, VI-27, f. 90v; AHCB, CC, Registre de deliberaciones, II- 23, f. 28v; II- 24, f. 155r; II- 26, f. 46r.

95 "Car uns per altres se destruexen, e a la darreria tornaria en dan de la Ciutat, qui no hauria carnicers ni carns" (ya que unos por otros se destruyen, y al final se volvería en daño para la ciudad, que no tendría ni carniceros, ni carnes). AHCB, CC, Registre de deliberacions, II- 5, f. 158r.

${ }^{96}$ A finales del siglo XV la ciudad de Barcelona permite a los extranjeros vender carne en la ciudad si aceptan las condiciones de la assegurança, pero a cambio han de contratar a los carniceros de la ciudad con un salario razonable, que en caso de no llegar a un acuerdo entre las partes será fijado por los consellers, el mostassaf y los prohomens de los carniceros. AHCB, CC, Manual, XIII-21, f. $113 \mathrm{v}$. 
de Normandía ${ }^{97}$, el mercado de la carne hasta finales del siglo XV no es un mercado cerrado controlado por las corporaciones de oficio, sino un mercado abierto donde trabajan carniceros integrados en una o más corporaciones de oficio y carniceros que trabajan por libre. A finales del siglo XV deja de haber carniceros en la ciudad que trabajen por libre y todos han de estar encuadrados en una de las tres corporaciones de oficio de carniceros de la ciudad, este hecho no se traduce en una desaparición de la competencia en el mercado de la carne. Entre la competencia perfecta y el monopolio puro hay un amplio espectro de posibilidades y, en Ruán, a finales del siglo XV hay tres corporaciones rivales y en competencia que venden el mismo tipo de producto $^{98}$. Tampoco hay que sobrevalorar el papel cohesionador de las corporaciones de oficio, ya que en su interior hay individuos de riqueza y situación social muy diferente, los cuales no tenían ni las mismas estructuras comerciales, ni los mismos objetivos económicos.

A pesar de que tradicionalmente se había pensado que un mercado organizado a través de corporaciones de oficio tenía que ser más ineficiente que un mercado donde no existieran, se ha podido observar que el mercado cárnico de Ruán era mucho más flexible que el de Barcelona y asumía con mucha más naturalidad las eventualidades que podían afectar a la cadena comercial ${ }^{99}$. La venta a estima de la carne, la inexistencia de precios máximos legales y el fomento de la competencia permitieron que los precios de venta de la carne se adaptaran sin problemas a los cambios que se producían en los procesos de producción; por tanto, los precios fluctuaron a lo largo de los dos siglos pero la ciudad no padeció graves problemas de abastecimiento. En Barcelona, en cambio, la rigidez impuesta por el municipio, que obliga a vender a peso, impone precios máximos y en determinados momentos marca cuotas de venta y concede monopolios legales, hará que la capacidad de reacción ante los cambios coyunturales en los costes de producción sea mucho más lenta, lo que acabará provocando carestías de manera regular. Estos problemas no solo los padece Barcelona, sino que también aparecen en otras ciudades donde el gobierno municipal ejerce un control directo del mercado de la carne, como es el caso de Venecia ${ }^{100}$. A pesar de que la mayor capacidad legislativa del municipio barcelonés le debería de dar más recursos para evitar la escasez de carne en la ciudad, el excesivo intervencionismo, unido a un desconocimiento de la mecánica del mercado les llevará a tomar decisiones erróneas, lo que provocará que una simple subida de precios se transforme en un problema de abastecimiento. No se puede desligar el intervencionismo que ejercía el municipio de Barcelona sobre la venta de carne, de la alta presión fiscal que recaía sobre el consumo de este alimento y que era imprescindible para la supervivencia financiera de la ciudad. Una bajada del consumo o un problema de desabastecimiento no solo repercutían en el bienestar de los habitantes de la ciudad, sino que también lo hacía en las endeudadas arcas del municipio $^{101}$. En el caso de Ruán, la carne no estará grabada con ningún impuesto hasta mediados del siglo XVI, cuando se impondrá el impuesto del pied fourché $e^{102}$.

La inexistencia de corporaciones de oficio fuertes también permitirá en Barcelona la entrada directa en el mercado de la carne de capitales externos al oficio

${ }^{97}$ F. Rivière, Guildes, pp. 36-45.

${ }^{98}$ G. Richardson, Guilds, laws, and markets, pp. 1-25; H. Swanson, The illusion, pp. 29-48.

99 Sobre la discusión alrededor de la eficiencia o ineficiencia económica de las corporaciones de oficio ver: S.R. Epstein, Craft guilds, pp. 155-174; S. Ogilvie, Can We Rehabilitate the Guilds?, pp. 1-63.

${ }^{100}$ F. Faugeron, Nourrir la ville, pp. 53-70.

101 R.A. Banegas, Comer carne, pp. 329-355.

${ }^{102}$ C.M. Robillard de Beaurepaire, Inventaire sommaire, p. 156. 
de la carnicería que desplazarán a los carniceros profesionales con menos capacidad económica, los cuales se verán obligados a trabajar como asalariados de los nuevos inversores. En Ruán, en cambio, las corporaciones de oficio y las mismas autoridades municipales y reales acotan el negocio de la carne a los miembros del oficio, a pesar de que, como se ha dicho con anterioridad, no todos tuvieran el mismo nivel económico ni la misma capacidad de negocio.

\section{BIBLIOGRAFÍA CITADA}

Aguadé, Santiago; Cabañas, $\mathrm{M}^{\mathrm{a}}$ Dolores, Comercio y sociedad urbana en la Castilla Medieval. La comercialización de la carne en Cuenca (1177-1500), "Anuario de Estudios Medievales" 4 (1984), pp. 504-516.

Bajet Royo, Montserrat, Policia de mercat a l'època medieval, "Revista de dret històric català” 2 (2002), pp. 121-143.

Banegas López, Ramón A.; Segovia Servián, Celia, Problemes en l'entrada de bestiar destinat a carn a la ciutat de Barcelona durant la segona meitat del segle $X V$. Una qüestió fiscal i de salut pública, "Acta Historica et archaeologica mediaevalia" 27-28 (2006-2007), pp. 121-142.

Banegas López, Ramón A., L'aprovisionament de carn a Barcelona durant els segles XIV i XV, Barcelona, Universitat de Barcelona, 2007. (Tesi doctoral)

Banegas López, Ramón A., Camino de la ciudad; conflictividad entre la capital y el principado de Cataluña en el proceso de aprovisionamiento de carne de Barcelona durante la Baja Edad Media (siglos XIV y XV), en Arízaga Bolumburu, Beatriz; Solórzano Telechea, Jesús Angel (eds.), Alimentar la ciudad en la Edad Media, Nájera. Encuentros Internacionales del Medievo 2008, Logroño, Instituto de Estudios Riojanos, 2009, pp. 113-131.

Banegas López, Ramón A., Comer carne y pagar impuestos. El impacto de las imposiciones municipales en el comercio barcelonés de carne durante el siglo XV, “Anuario de Estudios Medievales" 39/1 (2009), pp. 329-355.

Banegas López, Ramón A., Consumption of meat in Western European Cities during the Late Middle Ages. A Comparative Study, "Food and History" 8/1 (2010), pp. 63-86.

Barrio Barrio, Juan Antonio, El abastecimiento y venta de carnes en Orihuela durante el reinado de Alfonso V (1416-1456), "Anales de la Universidad de Alicante. Historia Medieval" 9 (1992-1993), pp. 257-278.

Batlle, Carme; Ramos, Lluïsa, Contribució a la història dels oficis de Barcelona: els carnissers del segle XIII, "Quaderns d'Estudis Medievals" 1 (1981), pp. 310-318.

Batlle, Carme, Vida i institucions polítiques, en Sobrequés i Callicó, Jaume (ed.), Història de Barcelona, Barcelona, Enciclopèdia Catalana, 1991-1997, vol. III, pp. 275-312.

Beauthier, Regine, Droit et genèse de l'État, Bruselas, Edition de l'Université de Bruxelles, 2002.

Bofarull y Sartorio, Manuel, Gremios y cofradías de la Antigua Corona de Aragón, Barcelona, Archivo de la Corona de Aragón, 1876.

Bonachía Hernando, Juan Antonio, Abastecimiento urbano, mercado local y control municipal: la provisión y comercialización de la carne en Burgos (siglo $X V)$, "Espacio, Tiempo y Forma, Serie III, Historia Medieval" 6 (1992), pp. 85-161.

Brereton, Georgina E.; Ferrier, Janet M. (eds.), Le Mesnagier de Paris, París, Librairie Générale Française, 1994. 
Carocci, Sandro (ed.), La mobilità sociale nel medioevo, Roma, École française de Rome, 2010.

Carrère, Claude, Barcelona, centre econòmic a l'època de les dificultats, 1380-1462, Barcelona, Curial, 1967.

Chaunu, Pierre; Gascon, Richard, Histoire économique et sociale de la France, vol. I, París, Presses Universitaires de France, 1977.

Clavel, Benoît, L'animal dans l'alimentation médiévale et moderne en France du nord (XIIIe-XVIIe siècles), "Revue archeologique de Picardie" 19 (2001), pp. 9-204.

Cochon, Pierre, Chronique Normande, Rouen, Librairie de la société de l'histoire de Normandie, 1870.

Comellas i Solé, Jordi, El mercat barceloní a través de la mostassaferia a principis del s. XV, en Ier Col-loqui d'Història de l'Alimentació a la Corona d'Aragó (Edat Mitjana), Lérida, Institut d'Estudis Ilerdencs, 1995, pp. 95-96.

De Lespinasse, René, Les métiers et corporations de la ville de Paris, vol. I, París, Imprimerie national, 1886-1897.

De Roover, Raymond, The Concept of the Just Price: Theory and Economic Policy, "Journal of Economic History" 18 (1958), pp. 418-438.

Descamps, Benoît, La destruction de la grande boucherie de Paris en mai 1416, "Hypothèses" 1 (2003), pp. 109-118.

Descamps, Benoît, De l'étable à l'étal: les circuits d'approvisionnement en viande à Paris à la fin du Moyen Âge, en Arízaga Bolumburu, Beatriz; Solórzano Telechea, Jesús Angel (eds.), Alimentar la ciudad en la Edad Media, Nájera. Encuentros Internacionales del Medievo 2008, Logroño, Instituto de Estudios Riojanos, 2009, pp. 333-350.

Doom, Vincent, Une communauté de métier au Bas Moyen Âge: l'Exemple des bouchers amiénois, en Guignet, Philippe (ęd.), Les peuple des villes dans l'Europe du Nord-Ouest (fin du Moyen Âge-1945), Villeneuve d'Ascq, CRHN-O, 2003, vol. I, pp. 117-146.

Durbec, Joseph A., La grande boucherie de Paris; notes historiques d'après des archives privés, XIIe-XVIIe siècles, París, Imprimerie nationale, 1957.

Epstein, S.R., Craft guilds in pre-modern economy: a discussion, "Economic history review" 61/1 (2008), pp. 155-174.

Faugeron, Fabien, Nourrir la ville, l'exemple de la boucherie venitienne à la fin du Moyen Âge, "Histoire Urbaine" 16/2 (2006), pp. 53-70.

García Marsilla, Juan Vicente, La jerarquía de la mesa, los sistemas alimentarios en la Valencia bajomedieval, Valencia, Diputació de València - Centre d'Estudis d'Història Local, 1993.

Hamon, Philippe, Les renaissances, 1453-1559, París, Belin, 2009.

Herlihy, David, Three patterns of social mobility in Medieval History, "Journal of Interdisciplinary History" 3/4 (1973), pp. 623-647.

Jones, Philip E., The butchers of London; a history of the worshipful company of butchers of the city of London, Londres, Secker and Warburg, 1976.

Lalinde Abadía, Jesús, La jurisdicción real inferior en Cataluña (Corts, veguers, batlles), Barcelona, Museu d'Història de la ciutat de Barcelona, 1966.

Laurioux, Bruno, Manger au Moyen Âge, París, Hachette, 2002.

Laurioux, Bruno, Une histoire culinaire du Moyen Âge, París, Honoré Champion, 2005.

Marín García, María A., Las carnicerías y el abastecimiento de carne en Murcia (1450-1500), "Miscelánea Medieval Murciana” 14 (1987-1988), pp. 51-99.

Matilla Tascón, Antonio, Abastecimiento de carne en Madrid (1477-1678), Madrid, Instituto de Estudios Madrileños, 1994. 
Mollat, Michel, Histoire de Rouen, Toulouse, Privat, 1969.

Nieto Jiménez, Lidio; Alvar Ezquerra, Manuel, Nuevo tesoro lexicográfico del español (s. XIV-1726), Madrid, Arco Libros, 2007.

Ogilvie, Sheilag, Can We Rehabilitate the Guilds? A Sceptical Re-Appraisal, Cambridge, University of Cambridge, 2007.

Orti Gost, Pere, Renda i fiscalitat en una ciutat medieval: Barcelona, segles XII-XIV, Barcelona, Consejo Superior de Investigaciones Científicas, 2000.

Richardson, Gary, Guilds, laws, and markets for manufactured merchandise in latemedieval England, "Explorations in Economic History" 41 (2004), pp. 1-25.

Riera Melis, Antoni, Estructura social y sistemas alimentarios en la Cataluña bajomedieval, "Acta Historica et Archaeologica Mediaevalia" 14-15 (1994), pp. 193-205.

Riera Melis, Antoni, Jerarquía social y desigualdad alimentaria en el Mediterráneo noroccidental en la Baja Edad Media. La cocina y la mesa de los estamentos privilegiados, "Acta Historica et Archaeologica Mediaevalia" 16-17 (1995-1996), pp. 193-195.

Riera Melis, Antoni, Pobreza y alimentación en el Mediterráneo Noroccidental en la Baja Edad Media, en La Mediterrània, àrea de convergència de sistemes alimentaris (segles V-XVIII): XIV Jornades d'Estudis Històrics Locals, Palma de Mallorca, Institut d'Estudis Baleàrics, 1996, pp. 39-72.

Rivière, François, Guildes, monopoles et oligopoles dans la Normandie de la fin du Moyen Âge: la réglementation des métiers est-elle hostile à la concurrence?, "Entreprise et histoire" 52/3 (2008), pp. 36-45.

Robillard de Beaurepaire, Charles Marie, Inventaire sommaire des archives communales antérieures à 1790: Ville de Rouen, Rouen, Imprimerie Julien Lecerf, 1887.

Smith, Adam, La riqueza de las naciones, Madrid, Alianza Editorial, 1994.

Stouff, Louis, La viande. Ravitaillement et consommation à Carpentras au XVe siècle, “Annales. Économies, Sociétés, Civilisations" 24/6 (1969), pp. 1431-1437.

Swanson, Heather, The illusion of economic structure: craft guild in Late Medieval English towns, "Past and Present" 21 (1988), pp. 29-48.

Van Uytven, Raymond, L'approvisionnement des villes des anciens Pays Bas au Moyen Âge, en L'approvisionnement des villes de l'Europe occidentale au Moyen Age et aux temps modernes, Auch, Comité départemental du tourisme du Gers, 1985, pp. 75-115.

Verdés Pijuan, Pere, Administrar les pecúnies e béns de la Universitat (Cervera, 1387-1516), Barcelona, Universitat de Barcelona, 2004. (Tesi doctoral)

Wolff, Philippe, Les bouchers de Toulouse du XIIe au XVe siècles, "Annales du Midi" 65 (1953), pp. 375-393.

Wood, Diana, Medieval Economic Thought, Cambridge, Cambridge University Press, 2002.

Fecha de recepción del artículo: marzo 2011

Fecha de aceptación y versión final: diciembre 2011 
